\title{
MODELING AND SIMULATION OF BUILDING ENERGY PERFORMANCE FOR PORTFOLIOS OF PUBLIC BUILDINGS
}

\author{
Young M. Lee \\ Fei Liu \\ Lianjun An \\ Huijing Jiang \\ Chandra Reddy \\ Raya Horesh \\ Paul Nevill \\ Estepan Meliksetian \\ Joe Emberson \\ Pawan Chowdhary \\ Al Paskevicous \\ Nat Mills \\ Young Tae Chae \\ Jane Snowdon \\ Jayant Kalagnanam \\ Elliott Jeyaseelan \\ Robert Forest \\ Chris Cuthbert \\ Tony Cupido \\ IBM T.J. Watson Research Center \\ McMaster University \\ 1101 Kitchawan Road \\ 1280 Main Street West \\ Yorktown Heights, NY 10598, USA \\ Hamilton, Ontario L8S 4M3, Canada \\ Michael Bobker \\ Janine Belfast \\ Building Performance Lab, CUNY Institute for Urban Systems \\ 137 E. 22nd St., \\ New York, NY 10010, USA
}

\begin{abstract}
In the U.S., commercial and residential buildings and their occupants consume more than $40 \%$ of total energy and are responsible for $45 \%$ of total greenhouse gas (GHG) emissions. Therefore, saving energy and costs, improving energy efficiency and reducing GHG emissions are key initiatives in many cities and municipalities and for building owners and operators. To reduce energy consumption in buildings, one needs to understand patterns of energy usage and heat transfer as well as characteristics of building structures, operations and occupant behaviors that influence energy consumption. We develop heat transfer inverse models and statistical models that describe how energy is consumed in commercial buildings, and simulate the impact of energy saving changes that can be made to commercial buildings including structural, operational, behavioral and weather changes, on energy consumption and GHG emissions. The analytic toolset identifies energy savings opportunities and quantifies the savings for a large portfolio of public buildings.
\end{abstract}




\section{INTRODUCTION}

In the United States, $40 \%$ of the nation's total energy consumption occurs in commercial and residential buildings (U.S. Dept of Energy 2006). The buildings also contribute to $45 \%$ of the country's greenhouse gas (GHG) emissions, which are linked directly to global climate change (EPA ESPM 2009). Global warming, caused by gradually increasing concentrations of GHG in the atmosphere, is one of the most significant crises that humans face today. Already, it is impacting our lives, for even small changes in the Earth's average temperature can increase the occurrences of severe weather conditions such as storms, floods and droughts, stimulate drastic climatic changes in all ecosystems, and initiate adverse impact on the health and lives of humans and other species.

The majority of greenhouse gases are emitted when fossil fuels are burned to produce heat and electricity. Once in the atmosphere, these gases, which include carbon dioxide $\left(\mathrm{CO}_{2}\right)$, methane $\left(\mathrm{CH}_{4}\right)$, chlorofluorocarbon (CFC), Tropospheric (ground level) ozone $\left(\mathrm{O}_{3}\right)$, nitrous oxide $\left(\mathrm{N}_{2} \mathrm{O}\right)$ and water vapor $\left(\mathrm{H}_{2} \mathrm{O}\right)$, create a "greenhouse effect" by trapping the thermal energy reflected off of the Earth's surface (Silver \& DeFries 1991). Out of all of the listed gases, $99 \%$ of the total greenhouse gas emissions consist of $\mathrm{CO}_{2}$, while a little less than the remaining $1 \%$ consists of $\mathrm{CH}_{4}$ and $\mathrm{N}_{2} \mathrm{O}$ together (EPA ESPM 2009a). Since a clear majority of GHG emissions consists of $\mathrm{CO}_{2}$, the term carbon dioxide equivalent $\left(\mathrm{CO}_{2} \mathrm{e}\right)$ is a common unit used to represent the weighted sum of the greenhouse impact of $\mathrm{CO}_{2}, \mathrm{CH}_{4}$, and $\mathrm{N}_{2} \mathrm{O}$ emissions (EPA ESPM 2009).

Today, the $\mathrm{CO}_{2} \mathrm{e}$ level serves as a significant instrument to all environmentalists, since emissions continue to rise. In fact, GHG emissions have been increasing rapidly for decades. In the year 1990, the total GHG emission was measured at 20.9 gigatons (Gt); however, by the year 2007, this number sharply increased to approximately $28.8 \mathrm{Gt}$. Research suggests that, by the year 2020 , the amount of total GHG emissions is expected to rise to roughly $34.5 \mathrm{Gt}$, and by the year 2030 , to $40.2 \mathrm{Gt}$, assuming that current trends in energy consumption continue. Similarly, research predicts that by the year $2030, \mathrm{CO}_{2} \mathrm{e}$ in the atmosphere will have increased from $400 \mathrm{ppm}$ (parts per million) (measured in year 2010) to 1,000 ppm, thereby potentially increasing the global average temperature of the Earth by $6^{\circ} \mathrm{C}$, or $10.8^{\circ} \mathrm{F}(\mathrm{OECD} / \mathrm{IEA}$ 2009). Such an increase in the Earth's global temperature would certainly lead to massive climatic changes, unimaginable natural disasters, and irreparable damage to the planet as a whole (OECD/IEA 2009).

Therefore, action must be taken. If we all participate in reducing global energy consumption and sufficient changes in government policies are made worldwide, the increase in the atmosphere's CO2e may be contained to a new target for $\mathrm{CO} 2 \mathrm{e}$ of $450 \mathrm{ppm}$ by 2030 , rather than $1,000 \mathrm{ppm}$, and a global average temperature increase may be contained to around $2{ }^{\circ} \mathrm{C}$ ( or $3.6^{\circ} \mathrm{F}$ ), rather than to $6^{\circ} \mathrm{C}$ (or $10.8^{\circ} \mathrm{F}$ ). However, scientists believe that if action is not taken within the next few years, this goal will end up completely out of reach (OECD/IEA 2009). The majority of the world's population either lives or works in a building; therefore, everybody has a responsibility and a role to play in reducing energy consumption, controlling GHG emissions, and confronting climate change and its potential impacts. End-use energy efficiency can contribute to more than $50 \%$ of total global energy conservation (OECD/IEA 2009).

Saving energy, improving energy efficiency and reducing greenhouse gas (GHG) emissions are key initiatives in many cities and municipalities and for building owners and operators. For example, New York City (NYC)'s government spends over \$1 billion a year on energy on their approximately 4,000 buildings (e.g., public schools, prisons, court houses, administrative buildings, waste water treatment plants, etc.), and is committed to reducing the City government's energy consumption and $\mathrm{CO}_{2}$ emissions by $30 \%$ by 2030 from 2005 levels through an initiative called plaNYC (City of New York 2007). NYC plans to invest, each year, an amount equal to $10 \%$ of its energy expenses in energy-saving measures over the next 10 years. The largest segment of NYC government buildings are the 1,400 K-12 public schools serving 1.1 million students and covering about 150 million square feet. The New York City Department of Education was interested in understanding how energy efficient their buildings are, what factors contribute to inefficiencies, what are the opportunities for improvement given budget constraints, and how 
much they can contribute to saving energy and reducing GHG emissions toward NYC's plaNYC initiative.

Another example is McMaster University in Hamilton, Ontario, Canada. The City of Hamilton's Corporate Energy Policy passed in 2007 aims to achieve a 20\% reduction in the energy intensity of Cityowned facilities and operations by 2020 from 2005 levels, or equivalently a 1.5\% reduction in energy per year. Vision 2020 is Hamilton's initiative for a strong, healthy, and sustainable city shared by citizens, City Council, businesses and organizations (hamilton.ca 2008). Vision 2020 is based upon four main principles consisting of fulfillment of human needs, maintenance of ecological integrity, provision for self-determination through public involvement in the definition and development of local solutions to environmental and development problems, and achievement of equity with the fairest possible sharing of limited resources. McMaster University, the 5th largest employer in Hamilton, spans 300 acres of property, has 60 buildings including a hospital with a 10 megawatt co-generation plant, and serves about 25,000 full-time students. McMaster was the first Ontario university to develop a sustainable building policy and has achieved four LEED ${ }^{\circledR}$ certified buildings on its campus, with three more registered for certification. McMaster University was interested in understanding both energy demand and supply aspects such as how energy efficient their buildings are, what factors contribute to inefficiencies, what operational schedules are effective for co-generation plant to supply electricity to the university hospital building versus purchasing electricity from the local utility, and how much they can contribute to saving energy and reducing GHG emissions toward Hamilton's Vision 2020 and Corporate Energy Policy.

In order to reduce energy consumption in buildings, however, one needs to understand patterns of energy usage and heat transfer as well as characteristics of building structures, operations and occupant behaviors that influence energy consumption. This understanding can be aided through development of scientific models which are based on physics, mathematics and statistics. The models can then be used to simulate the impact of possible changes that can be made to buildings on energy consumption, energy costs and GHG emissions, and provide decision support for making buildings more energy efficient. The changes can be structural changes such as retrofits (e.g., new boiler, insulation, windows or roof), operational changes such as operating hours, behavioral changes such as running appliances at different times of the day when electricity prices are lower, and external changes such as weather factors. The models can also be used for optimizing the changes that can be made to the buildings given an energy conservation target. Developed along this effort is the IBM Building Energy and Emissions Analytics ( $\left.i-B E E^{T M}\right)$ Toolset, a new strategic planning analytical tool which assesses, benchmarks, diagnoses, tracks, forecasts, simulates and optimizes energy consumption in building portfolios. As initial efforts of this initiative, IBM collaborated with the City University of New York (IBM 2011a) to analyze energy use in the portfolio of K-12 public school buildings in New York City, and McMaster University (IBM 2011b) to analyze energy use in the portfolio university campus buildings and to identify energy saving opportunities.

The rest of the paper is organized as follows. In Section 2, the data flow and analytics of the building energy analytics toolset are presented. In Section 3, the heat transfer model and inverse modeling approach for estimating heat transfer coefficients are described. Then, Section 4 shows the novel statistical models that integrated multiple regression models and a time series model of building energy. In Section 5 , examples of simulation and optimization are shown. Finally, closing remarks and future research areas are provided in Section 6.

\section{DATA FLOW AND ANALYTICS OF BUILDING ENERGY ANALYTICS TOOLSET}

The building energy models in $i-B E E^{T M}$ are developed from data coming from multiple sources. Figure 1 describes how various data are collected and assembled into a common database and used for deriving models and analytics.

One type of data used for models is data coming from building management system (BMS) such as temperature, relative humidity and flow rate of supply air and return air from/to air handling units (AHU) and variable air volume (VAV) boxes, which provide warm or cool air into various rooms inside buildings. Data collected from various sensors such as temperature, humidity and occupancy are also used. 
The sensor data can be recorded and collected through the BMS. Data can also come from meters and sub-meters that measure energy use such as electricity, natural gas, steam and chilled water for the whole building or part of the buildings or equipment. Other data elements include: energy bills, e.g., monthly bills for electricity, natural gas and steam consumption; building characteristics such as gross floor area (GFA), age of building, number of occupants, wall area, window area, roof area, number of floor, \% of building cooled and heated, operating hours, number of computers and other equipment such as refrigerators, freezers etc; thermal loads and plug loads; weather data for historic and current conditions such as temperature, humidity, solar radiation and wind; and real-time electricity prices from the local utility. Data from the Environmental Protection Agency (EPA) can also be used for calculating source energy and greenhouse gas (GHG) emissions for which a building is responsible (EPA 2009). Site energy is the amount of energy consumed by a building for heating, cooling, lighting, plug loads, and so on. Source energy is the amount of energy required to generate and transport the energy requirements of the building.

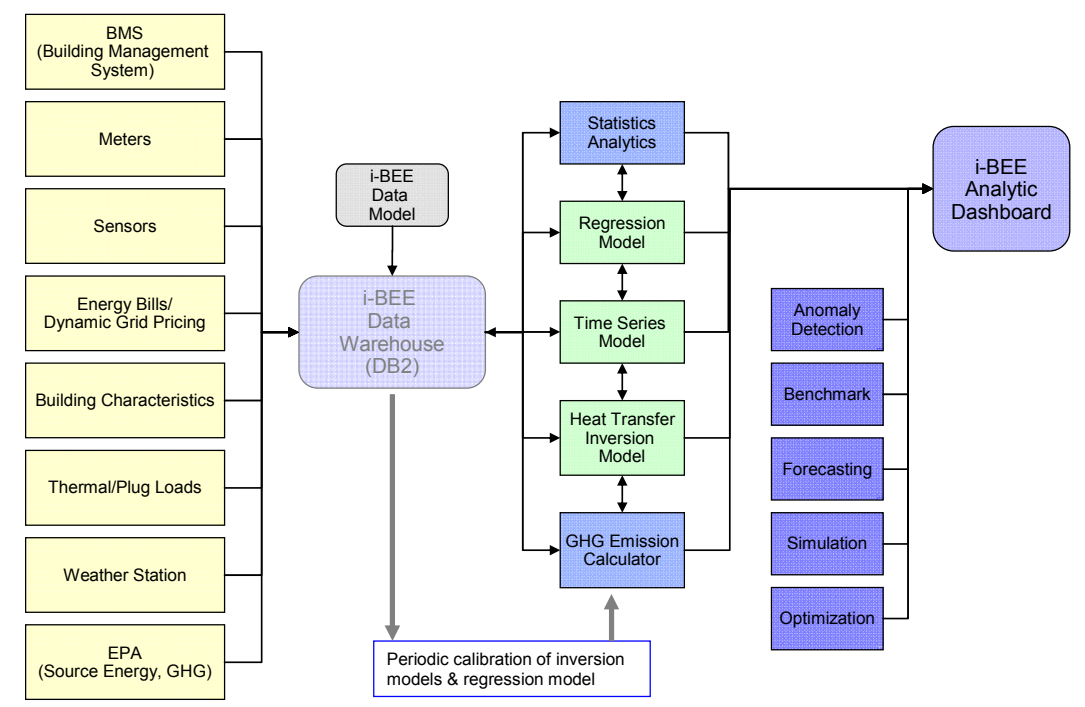

Figure 1: Data flow and analytics

The $i-B E E^{T M}$ data described above is organized into a database in a data warehouse, which is designed through a data model that defines the relationship between data elements. The data from the database is used in populating three fundamental base models: heat transfer inverse model, multivariate regression model, and time series model. The models are described below in the following sections. These three base models are also calibrated as new data sets are brought into the database in such a way that the model stays accurate even if the building energy performance degrades over time. In addition to the model, basic statistical analyses including temporal and spatial analysis, and GHG emissions calculations are done for the buildings in the portfolio. Using the three base models in an integrated way, various analytic tasks can be performed. One is anomaly detection for energy use for each building. This capability identifies abnormal energy consumption for a building or a part of the building by comparing actual energy consumption with predicted energy consumption and calculating upper and lower control bounds. Another task is benchmarking, which computes energy performance indicators of each building for each energy type and for each type of energy loads (e.g., base load, heating load and cooling load), and identifies under-performing buildings, which can be candidates for energy efficiency improvements. Another task is forecasting future energy consumption in the short-term (i.e., for the next 24 hours) and longer-term (e.g., for the next few months). Another task is simulation (what-if analysis) of changes that could be made to building structures, operations and occupant incentives on energy consumption and GHG emissions. Fi- 
nally, several types optimization can also be done as explained in the sections below. All the analytics and reports are accessible to users through an analytics dashboard.

\section{HEAT TRANSFER MODELING AND INVERSION}

In this section, we describe how thermal energy is used to provide a comfortable climate, e.g., temperature and humidity, inside a building using thermal physics principles. Figure 2 shows a simplified view of heat transfer in a building. Building occupants would like to have comfortable temperature and humidity inside the building, However, since buildings are not perfectly insulated nor blocked from sun light, warm and humid climate conditions outside a building come into the building during the summer season, and cold and dry air comes into the building during the winter season making the inside climate uncomfortable for the occupants. In order to compensate for the influence of outside climate, heating ventilation and air conditioning (HVAC) systems including boilers, air conditioners, chillers and AHUs are used to provide warm or cool air into the building to maintain a comfortable climate. Typically heat transfer from outside air into the house involves heat transfer through walls, windows, roof and the ground (foundation). The heat transfer includes heat conduction (e.g., heat flows through wall materials), heat convection (e.g., heat flows through the air from the wall into the inside space of a house), solar radiation (e.g., solar energy into the outside wall or into the inside wall or furniture through windows), infiltration of outside air into the house through cracks around windows, doors and opened windows and doors, and latent heat (e.g., heat of vaporization and heat of condensation of moisture in the air). From the HVAC side, chillers and boilers produce steam, hot water or chilled water, which is then transferred to the buildings where heat exchangers convert them into warm and cold air with a certain supply temperature, humidity and flow rate, and blow them to each zone of the building using AHUs and other fan systems.

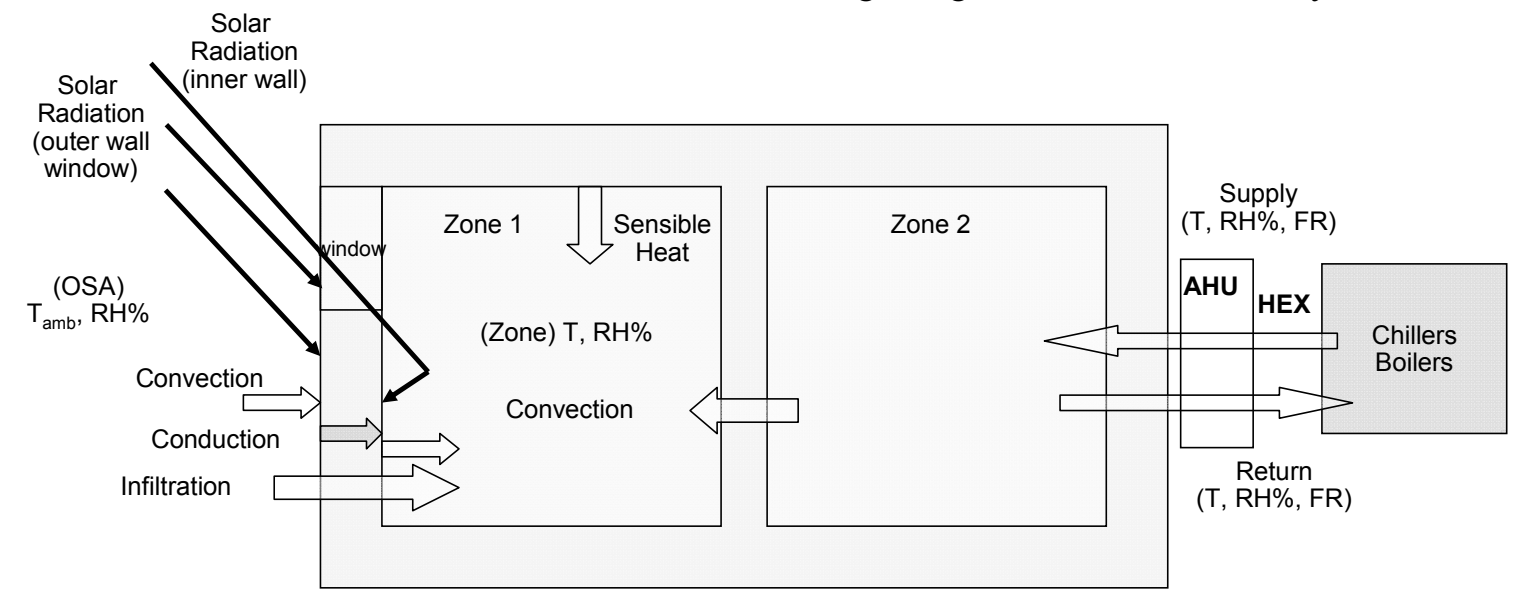

Figure 2: Simplified view of heat transfer in a building

The heat transfer can be simplified as the following set of equations:

$$
\begin{gathered}
\rho_{\text {wall }} V_{\text {wall }} C_{p, \text { wall }} \frac{d T_{O}}{d t}=k_{\text {wall }}\left(T_{I}-T_{O}\right) \frac{V_{\text {wall }}}{d_{\text {wall }}^{2}}+h_{q} A_{z}\left(T_{\text {amb }}-T_{O}\right)+\dot{Q}_{\text {sol }-O} \\
\rho_{\text {wall }} V_{\text {wall }} C_{p, \text { wall }} \frac{d T_{I}}{d t}=k_{\text {wall }}\left(T_{O}-T_{I}\right) \frac{V_{\text {wall }}}{d_{\text {wall }}^{2}}+h_{q} A_{z}\left(T_{z}-T_{I}\right)+\dot{Q}_{\text {sol-I }} \\
\rho_{z} V_{z} \frac{d W_{z}}{d t}=\dot{m}_{s y s}\left(W_{\text {sys }}-W_{z}\right)+\dot{m}_{\text {inf }}\left(W_{\text {amb }}-W_{z}\right)+\dot{m}_{w-l a t e n t}
\end{gathered}
$$




$$
\rho_{z} V_{z} C_{p} \frac{d T_{z}}{d t}=\dot{m}_{s y s} C_{p}\left(T_{s y s}-T_{z}\right)+\dot{m}_{\mathrm{inf}} C_{p}\left(T_{a m b}-T_{z}\right)+\dot{Q}_{\text {sens }}+\dot{Q}_{\text {struc }}+\dot{Q}_{w-\text { latent }}
$$

Equation (1) is enthalpy balance on the outer wall, (2) is enthalpy balance of the inner wall, (3) is mass (moisture) balance inside the building (zone), and (4) is enthalpy balance inside of the building (zone). Here,

$$
\begin{array}{ll}
T_{z}, T_{O}, T_{I}, T_{a m b}, T_{s y s} & \begin{array}{l}
\text { are temperatures of zone, outer wall, inner wall and outside air (ambient) } \\
\text { and HVAC system } \\
\text { are densities of wall and the zone (inside air), }
\end{array} \\
\rho_{\text {wall }}, \rho_{z} & \begin{array}{l}
V_{z}, V_{\text {wall }}, A_{z}, A_{\text {wall }}, A_{\text {win }}, A_{\text {roof }}, d_{\text {wall }} \text { are volumes of zone, wall; areas of the zone, wall, windows, roof; } \\
\text { thickness of wall, } \\
\text { are specific heat of wall and inside air, }
\end{array} \\
C_{p, \text { wall }}, C_{p} & \text { are coefficients of heat conduction of wall, heat convection coefficient of } \\
k_{\text {wall }}, h_{q}, h_{q, \text { wall }}, h_{q, w i n}, h_{q, \text { roof }} & \text { the overall zone, wall, window and roof, } \\
\dot{m}_{\text {inf }}, \dot{m}_{s y s} & \text { are flow rates of infiltration and system (HVAC) } \\
\dot{Q}_{\text {sol-I }}, \dot{Q}_{\text {sol-O }} & \text { are rates of solar radiation hitting inner wall and outer wall, } \\
\dot{Q}_{\text {struc }} & \text { is the heat flow from outside to inside the building through the building } \\
\dot{Q}_{w-l a t e n t}=\dot{m}_{w-l a t e n t} \Delta H_{w-l a t e n t} & \text { structure (e.g., wall, window and roof), } \\
\dot{Q}_{\text {sens }} & \text { is the heat flow of latent heat, } \\
\dot{Q}_{s y s}=\dot{m}_{s y s} C_{p}\left(T_{s y s}-T_{z}\right) & \text { is the heat flow of sensible heat, } \\
& \text { is the heat flow from HVAC system into the building. }
\end{array}
$$

For heat transfer inverse modeling of buildings, often there isn't enough sensor data or meter data to allow for estimation of all the physical parameters that support the complexity of the heat transfer model (e.g., equations). Therefore, the heat transfer equations above can be simplified, and heat transfer coefficients are often expressed in terms of R-values and U-values, i.e., $R_{\text {wall }}, R_{\text {roof }}, U_{\text {win }}$, which are heat resistances of wall and roof, and heat transfer coefficient of window.

In equations (1) - (4), the parameters that are not known are $k_{f, \text { wall }}, h_{q}, h_{q, \text { wall }}, h_{q, \text { win }}, h_{q, \text { roof }}, \dot{m}_{\text {inf }}$ which represent heat conduction coefficient of the wall, heat convection coefficients of the building envelope, wall, window and roof, and infiltration coefficient of the building envelope. The methods for estimating these kinds of parameters through measured data is called inverse modeling (Beck and Woodbury 1998). The procedure for estimating parameters for inversion modeling goes as follows:

1. Guess initial values of the parameters

2. Compute expected energy consumption from heat transfer equations, $Q_{\text {calc }}$

3. Compute the residue (difference between calculated \& measured), $Q_{\text {calc }}-Q_{\text {meas }}$

4. Find the parameter values that minimize the sum of residue $\sum_{i=1}^{N}\left(Q_{\text {calc }}-Q_{\text {meas }}\right)^{2}$

Depending on the availability of data for the building, the observed data might not allow for the estimation of all parameters. For the portfolio of commercial buildings analyzed, we generated an innovative procedure to address the issue. First, we derive a static heat transfer model by integrating the differential 
equations described above by integrating them over heating seasons and cooling seasons. Then, using the energy consumption data, we estimate the overall heat transfer coefficient and solar contribution for each building. Lastly, a clustering method is used to separate the overall heat transfer into thermal resistance of the wall, roof, and window for a collection of similar buildings. The details of this approach will be published in a separate paper (An et al. 2011).

\section{STATISTICAL MODELS}

We developed statistical methods to help understand the energy usage patterns for the portfolios of New York City's K-12 public school buildings and campus buildings of McMaster University. The Variable Base Degree Day (VBDD) regression model (ASHRAE 2009) is a popular approach to analyze energy consumption, which assumes an independent error structure for the regression model. The assumption may not be realistic in practice, especially for our application with a large portfolio of buildings. A new method, which incorporates building heterogeneity and the dependent error structure, is thus developed.

We developed a multi-step statistical analysis procedure, which combines the multivariate regression model, the VBDD regression model and the Auto Regressive Integrated Moving Average (ARIMA) model (Brockwell and Davis 2006), to assess energy use and identify energy saving opportunities for large portfolios of buildings. In the first step, we build a regression model which correlates the energy consumption with building characteristics. The energy related building characteristics are then identified through the stepwise variable selection technique. The results are valuable in providing building energy performance scores for the whole portfolio. Additionally, it can predict the energy consumption of buildings of similar characteristics. In the second step, to accommodate building heterogeneity, we build VBDD regression models separately for each building. For VBDD model, the total monthly energy usage data for building $i$, in period $t$ is denoted $y_{i t}$, and is modeled as:

$$
y_{i t}=b_{i}+c_{i} C D D_{t}\left(T_{i}^{(b)}\right)+h_{i} H D D_{t}\left(T_{i}^{(b)}\right)+\varepsilon_{i t}
$$

where $b_{i}$ is the base load usage, $c_{i}$ is the cooling coefficient, $h_{i}$ is the heating coefficient, and $\varepsilon_{i t}$ are the error terms reflecting the month-to-month variations that can not be explained by base, heating or cooling usage. We further restrict that $b_{i}>0, c_{i}>0$ and $h_{i}>0$. The heating degree day (HDD) and the cooling degree day (CDD) for building $i$ in month $t$ are defined as

$$
H D D_{t}\left(T_{i}^{(b)}\right)=\sum_{d=1}^{d_{t}}\left(T_{i}^{(b)}-T_{i t d}\right)^{+} \text {, and } C D D_{t}\left(T_{i}^{(b)}\right)=\sum_{d=1}^{d_{t}}\left(T_{i t d}-T_{i}^{(b)}\right)^{+} \text {. }
$$

Here, $T_{i t d}$ is the outdoor temperature for building $i$ on day $d$ of month $t, i \in\{1, \ldots, n\}, t \in\{1, \ldots, m\}$, $d \in\left\{1, \ldots, d_{t}\right\}$, and $T_{i}^{(b)}$ is the balance-point temperature for building i. $H D D_{t}\left(T_{i}^{(b)}\right)$ and $C D D_{t}\left(T_{i}^{(b)}\right)$ are the cumulative heating and cooling energy usage for month $t$ when the balance point temperature is set to be $T_{i}^{(b)}$.

These models are used to separate the base load energy consumption from the weather dependent usage. The results in this step consist of the base temperature estimates, as well as the estimated coefficients for HDD and CDD for all buildings. In the third step, we further conduct root cause analysis by building the multivariate regression models for the results from the VBDD model, from which the performance scores can be derived for base load, heating, and cooling. The multivariate regression model takes the form

$$
y_{i}=x_{i 1} \beta_{1}+x_{i 2} \beta_{2}+\ldots+x_{i p} \beta_{p}+\varepsilon_{i}
$$

where $y_{i}$ is the quantity of our interest, typically referred to as the response variable, and $x_{i 1}, \ldots, x_{i p}$ are the $p$ predictor variables, and $\beta_{1}, \ldots \beta_{p}$ are the regression coefficients and $\varepsilon_{i}$ is the error term. 
Finally, in the last step, we model the dependent error structure through the ARIMA model. Recall that $\hat{\varepsilon}_{i t}, t=1, \ldots, m$, are the estimated error terms from the VBDD models (5). The time series modeling is conducted for each individual building independently. Firstly, we remove the seasonal patterns by using a regression model, with $\hat{\varepsilon}_{i t}$ being the response variable and the 12 monthly seasonal factors being the predictor variables. To avoid the collinearity issue, we set the monthly seasonal factor for December equal to 0 . We denote the error terms from (5) after removing the seasonal patterns by $\widetilde{\varepsilon}_{i t}$. Then, we model the dynamic structure of $\widetilde{\varepsilon}_{i t}$ by the autoregressive integrated moving average (ARIMA) model. The ARIMA model is developed to model time series data, for better understanding the present data and accurately forecasting future data points (Brockwell and Davis 2006). Despite its popularity in statistical literature, the ARIMA model has been rarely used in the context of building energy, partly because of its complex modeling schemes. Nevertheless, the ARIMA model provides a more flexible, possibly nonstationary structure to model building energy patterns, which is essential for simultaneously modeling of a large number of buildings. ARIMA takes a form

$$
\left(1-\sum_{\ell=1}^{p} \phi_{i \ell} L^{\ell}\right)(1-L)^{\ell} \widetilde{\varepsilon}_{i t}=\left(1+\sum_{\ell=1}^{q} \theta_{i \ell} L^{\ell}\right) \eta_{i t}
$$

where $L$ is the lag operator, $L \widetilde{\varepsilon}_{i t}=\widetilde{\varepsilon}_{i, t-1} ; p, d, q$ are non-negative integers and are the orders of autoregressive, integrated, and moving average parts of the model; $\left\{\phi_{i \ell}, \ell=1, \ldots, p\right\}$ and $\left\{\theta_{i \ell}, \ell=1, \ldots, q\right\}$ are the parameters associated with the auto-regressive and moving average parts of the model; and $\eta_{i t}$ are mutually independent standard normal random variables. The ARIMA models are the most general class of models for forecasting a time series which can be stationarized by transformations such as differencing. In fact, the order of the integrated part $d$ reflects the trend of the data (e.g., $d=0$ no trend, $d=1$ linear trend, $d=2$ quadratic trend, etc.), while $p$ and $q$ control how fast the auto-correlation decays.

The technique provides an integrated analysis for building heterogeneity, the weather dependent patterns and the temporal dependent patterns. It has wide applicability in anomaly detection, forecasting, root cause analysis for building energy portfolios. The technique is described by the schematic given in Figure 3. The details of the techniques are explained in Liu et al. (2011).

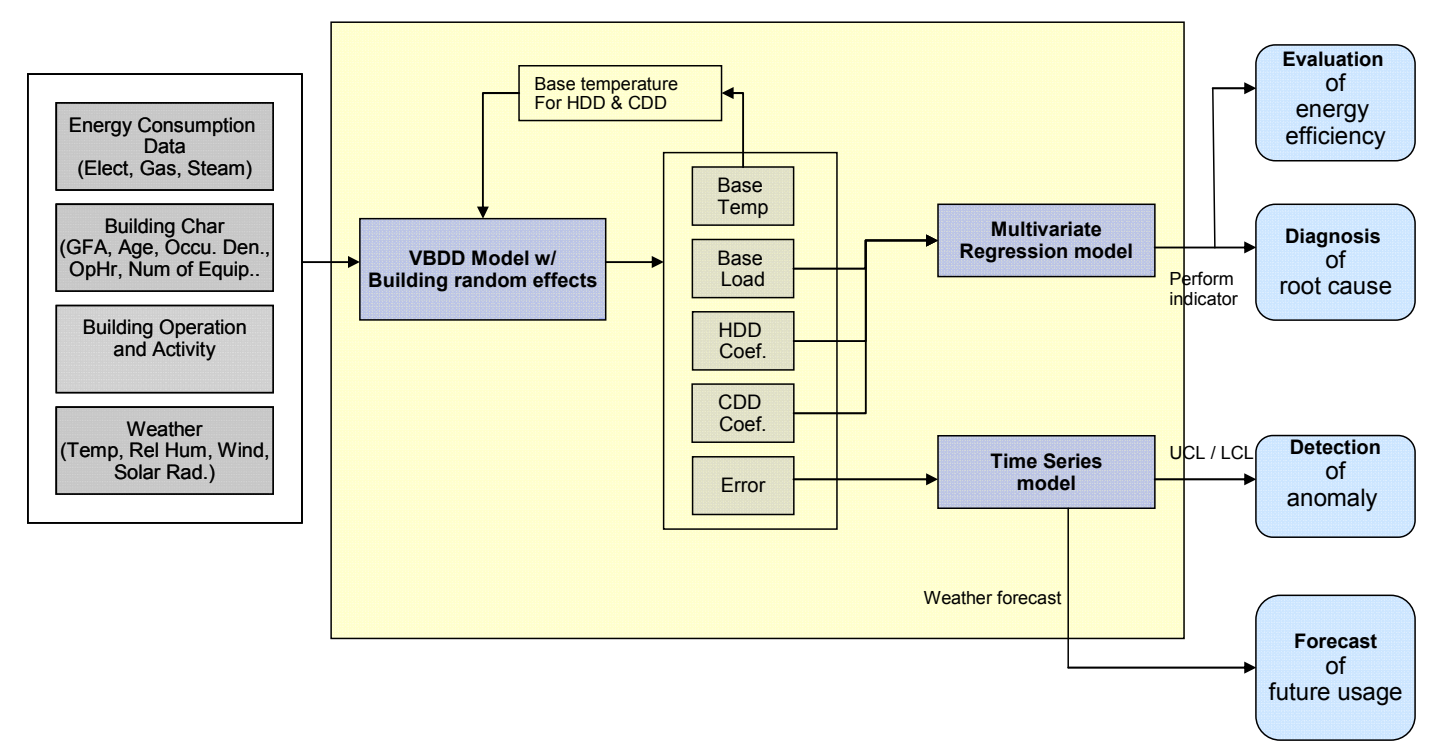

Figure 3: Integrated statistical approach 


\section{SIMULATION AND OPTIMIZATION}

The models for building energy are used for simulation and optimization. As shown in Figure 4, the models are developed using the collected building information such as data from meters, sensors, energy bill, weather and building characteristics. For simulation, different types of changes that influence the building energy consumption can be simulated by computing estimated changes (hopefully reduction) of energy consumption, costs and GHG emissions. One or more of these changes can be entered into the models, and one or more models compute the estimated energy consumption, costs and GHG emissions. The first types of changes that can be simulated are building structural changes such as retrofits, which include improving insulation of building envelope, replacing boilers, changing single pane windows to double pane, and installing shading to the window. The second types of changes are building operational changes such as decreasing operating hours of buildings, changing the set point for heating or cooling, running electric appliances at different times of the day, and so on. The other types of changes are ones related to behavior or building occupants, who may shut off lighting when they leave a room, refraining from opening windows when heaters or air-conditioners are in operation, or turning off personal computers (PCs) before leaving the building or going to bed. Finally, external changes such as specific weather conditions including temperature, humidity and solar radiation can also be simulated to understand their impact on energy consumption, costs and GHG emissions.

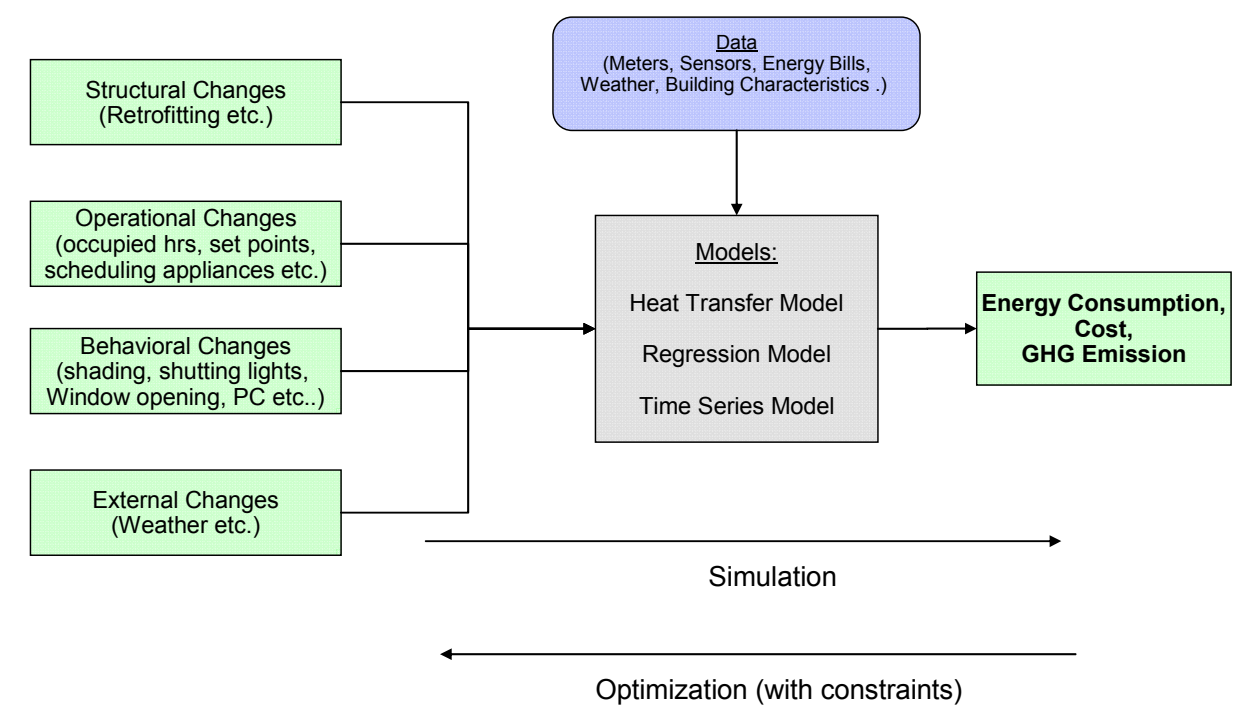

Figure 4: Model-based simulation and optimization

The models can also be used for optimization tasks. Often, building owners or operators have mandates or targets for energy savings, peak demand level, GHG emission reductions or budget for retrofitting. In this case, the models can be used to determine what changes should be made for specific buildings at specific times to achieve the target in presence of constraints such as comfort level of occupants and limited resources. As illustrated in Figure 4, when information flows from left to right, simulation analyses are conducted to determine the impact of changes. When information flows from right to left to determine the effective changes to achieve energy saving goal, optimization analyses are conducted.

In this section, we describe a couple of examples of simulation. The first example is simulation of building insulation changes on energy consumption. $i-B E E^{T M}$ computes thermal coefficients of individual buildings in the portfolio, such as $\mathrm{R}$ values for walls and roof, $\mathrm{U}$ value of windows and their infiltration coefficient, $\dot{m}_{\text {inf }}$. When a building is picked for analysis from the analytic dashboard, as shown in Figure 5 , all those thermal coefficients are displayed and thermal energy for each month for a whole year is 


\section{Lee et al.}

computed and shown. Then, a user changes one or more of the coefficients. In the example in Figure 5, a user changes the R-value of the roof from 16.68 to $40\left[\mathrm{ft}^{2} .{ }^{\circ} \mathrm{F} \cdot \mathrm{hour} / \mathrm{Btu}\right]$ by hypothetically increasing insulation of the roof of the building. The toolset computes the energy savings by month and for the whole year. The yearly thermal energy consumption decreases by $325,792 \mathrm{kBtu}$ from $8,124,482 \mathrm{kBtu}$ to 7,798,690 kBtu.

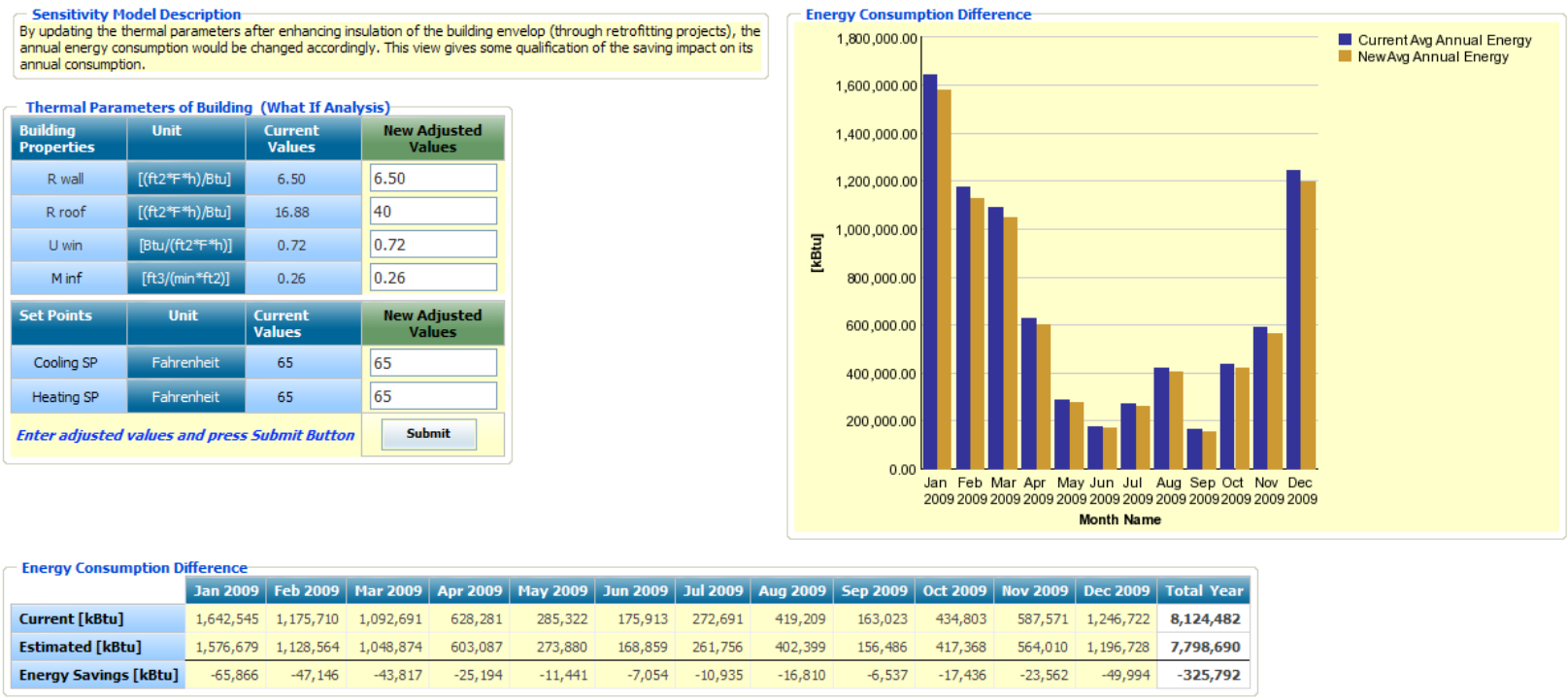

Figure 5: Simulation of building insulation change

The second example of simulation is for changing the thermostat set point of the building during the heating season. As shown in Figure 6, for another building in the portfolio, the heating set point is changed from $65{ }^{\circ} \mathrm{F}$ to $62{ }^{\circ} \mathrm{F}$. The corresponding impact is computed as a decrease of yearly energy consumption by $653,703 \mathrm{kBtu}$ from 5,045,111 kBtu to 4,391,408 kBtu.
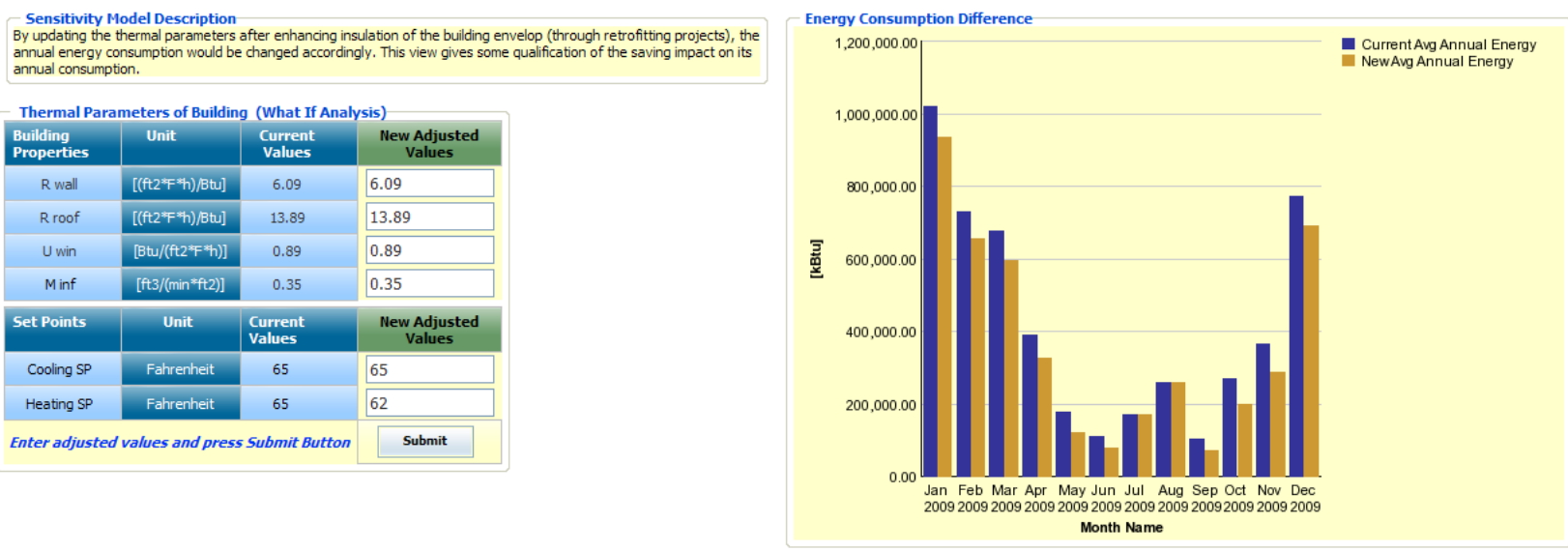

Energy Consumption Difference

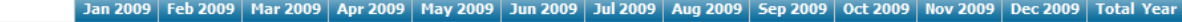

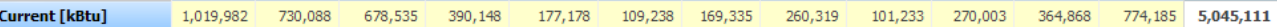

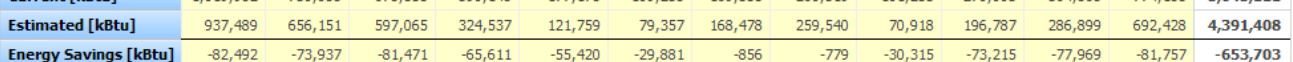

Figure 6: Simulation of thermostat set point 
There are several optimization capabilities that are developed for $i-B E E^{T M}$. These optimizations utilize the three base models described above. In this paper, we briefly described the optimization capabilities due to the limited space in the paper, but details of optimization capabilities will be described in a subsequent paper. One such optimization capability is for optimal retrofit planning. This optimization tool determines which buildings should be retrofitted, and which retrofit should be done given a limited budget for the whole building portfolio, e.g., K-12 schools, and certain goals for energy reduction and GHG emissions that should be met.

Another optimization capability in $i-B E E^{T M}$ is the optimal scheduling of energy consuming activities. The price of electricity changes drastically during the day although individual residential building owners or tenants of commercial building may not see the dynamics of the price in their electricity bill. However, typically commercial building owners or managers pay electricity bills based on how much electricity is used during various times of the day and also by the peak demand. In addition, consuming electricity during a peak demand time such as early afternoon would have negative environmental impact since the local utility company may have to operate additional power plants to meet the peak demand thus emitting more GHG. This optimization capability determines the best ways of scheduling energy consuming activities (e.g., laundry, dishwashing, after school activities) so that the peak demand is lowered and energy is used when the price is lower. Other optimization capabilities include the optimal operation of onsite generation and co-gen and energy storage; the optimal capacity sizing of HVAC equipment; the optimal energy pricing structure for modifying behaviors of building owners and tenants, i.e., demand response and optimal contracting of energy purchase.

\section{CLOSING REMARKS}

Since buildings are responsible for $40 \%$ of the U.S.'s total energy consumption and $45 \%$ of its total GHG emissions, all of us, who live and work in buildings have a responsibility and role to play in reducing energy consumption and controlling the GHG emissions, confronting climate change and its potential impacts. Science and mathematics can play an important role in helping us accurately assess how we consume energy in buildings and what we can do to save energy, make buildings energy efficient and reduce GHG emissions. In this paper, we introduced a building energy analytics toolset that is based on a novel integrated approach that combines thermal physics models, statistical models and mathematical models. We applied the new toolset for two portfolios of commercial buildings; one for NYC K-12 public school buildings and another for McMaster University campus buildings, and deployed the toolset on IBM's cloud-based computing environment successfully. Energy savings, energy efficiency and GHG emissions from buildings have become critical issues, and therefore there are many opportunities to be explored to make an impact. Let's build smarter buildings together.

\section{REFERENCES}

An, L., R. Horesh, Y. Chae, and Y. M. Lee. 2011. "Estimation of Thermal Parameters of Buildings Through Inverse Modeling and Clustering." Working paper. IBM TJ Watson Research Center.

ASHRAE. 2009. ASHRAE Handbook: Fundamentals (SI Edition). Atlanta, GA: American Society of Heating, Refrigerating and Air-Conditioning Engineers.

Beck, J. V., and K. A. Woodbury. 1998. "Inverse Problems and Parameter Estimation: Integration of Measurement and Analysis." Measurement Science Technology 9:839-847.

Brockwell, P. J., and R. A. Davis. 2006. Time Series: Theory and Methods. 2nd ed. Springer.

City of New York. 2007. plaNYC 2030: A Greener, Greater New York. Accessed September 23, 2010. http://www.nyc.gov/html/planyc2030/html/home/home.shtml.

EPA. 2009. "Energy Star Performance Ratings Methodology for Incorporating Source Energy Use." U.S. Environmental Protection Agency. Accessed September 23, 2010, http:/www.energystar.gov/ia/business/evaluate_performance/site_source.pdf. 
EPA ESPM (EnergyStar Portfolio Manager). 2009. "Greenhouse Gas Inventory and Tracking in Portfolio Manager.” U.S. Environmental Protection Agency (EPA) August 2009. Accessed February 8, 2010. http://www.energystar.gov/ia/business/evaluate_performance/Emissions_Supporting_Doc.pdf.

hamilton.ca. 2008. City Housing Hamilton Demonstrates Commitment to Energy Conservation. Hamilton, Ontario, Canada. Accessed September 23, 2010. http://www.hamilton.ca/NewsandPublications/NewsReleases/2008News/01-17-08ka.htm.

IBM. 2011a. "City university of New York and IBM to Reduce Energy Consumption in Public School Buildings." Accessed May 1. http://www.ibm.com/press/us/en/pressrelease/34080.wss.

IBM. 2011b. "IBM Works With McMaster University to Create First Canadian Energy-Smart Buildings on Campus." Accessed May 1. http://www-03.ibm.com/press/us/en/pressrelease/33838.wss.

Liu, F., H. Jiang, Y. M. Lee, and J. Snowdon. 2011. "Statistical Modeling for Anomaly Detection, Forecasting and Root Cause Analysis of Energy Consumption for a Portfolio of Buildings." In Proceedings of IBPSA2011.

OECD/IEA. 2009. World Energy Outlook 2009. Organization for Economic Cooperation and Development/ International Energy Agency, France. Accessed September 23, 2010. www.worldenergyoutlook.org/2009.asp.

Silver, C. S., and R. D. DeFries. 1991. One Earth One Future. National Academy of Sciences.

U.S. Dept. of Energy. 2006. Buildings Energy Data Book. U.S. Department of Energy. Accessed September 23, 2010. http://buildingsdatabook.eren.doe.gov/TableView.aspx?table=1.1.1.

\section{AUTHOR BIOGRAPHIES}

YOUNG M. LEE is a Research Staff Member in the Mathematical Sciences Department of IBM's T.J. Watson Research Center, U.S.A. His email address is ymlee@us.ibm.com.

FEI LIU is a Research Staff Member at IBM Watson Research Center. She holds a Ph.D. in Statistics from Duke University in North Carolina, USA. Her email address is feiliu@us.ibm.com.

LIANJUN AN is a Researcher in the Mathematical Sciences Department of IBM's T.J. Watson Research Center, U.S.A. His email address is alianjun@us.ibm.com.

CHANDRA REDDY is a Researcher in the Mathematical Sciences Department of IBM's T.J. Watson Research Center, U.S.A. His email address is creddy@us.ibm.com.

NATHANIEL MILLS is a Senior Technical Staff Member in the Mathematical Sciences Department of IBM’s T.J. Watson Research Center, U.S.A. His email address iswnm3@us.ibm.com.

PAWAN CHOWDHARY is a Senior Engineer in the Mathematical Sciences Department of IBM's T.J. Watson Research Center, U.S.A. His email address is chowdhary@us.ibm.com.

ESTEPAN MELIKSETIAN is a Software Engineer in the Mathematical Sciences Department of IBM's T.J. Watson Research Center, U.S.A. His email address is emelikse@us.ibm.com.

RAYA HORESH is a Research Staff Member in the Mathematical Sciences Department of IBM's T.J. Watson Research Center, U.S.A. Her email address is rhoresh@us.ibm.com.

PAUL NEVILLE is a IBM Certified Solution Expert in Business Analytics consulting at IBM's T.J. Watson Research Center, U.S.A. His email address is pnevill@us.ibm.com. 
YOUNG TAE CHAE is a Post Doctoral Researcher in the Mathematical Sciences Department of IBM's T.J. Watson Research Center, U.S.A. His email address is ychae@us.ibm.com.

HUIJING JIANG is a Post Doctoral Researcher in the Mathematical Sciences Department of IBM's T.J. Watson Research Center, U.S.A. His email address is huijiang@us.ibm.com.

JANE L. SNOWDON is a Senior Manager, Smarter Building Research, in the Industry Solutions and Emerging Business Department of IBM's T. J. Watson Research Center, Yorktown Heights, NY, U.S.A. Her email address is snowdonj@us.ibm.com.

JAYANT KALAGNANAM is a Senior Manager in the Mathematical Sciences Department of IBM's T.J. Watson Research Center, U.S.A. His email address is jayant@us.ibm.com.

AL A. PASKEVICIUS is the Utilities Services Manager for McMaster University and has served in this capacity since 1988. His email address is paskevi@mcmaster.ca.

JOSEPH EMBERSON is the Chief Operating Engineer for McMaster University in Hamilton, Ontario Canada. His e-mail address is embers@mcmaster.ca.

CHRIAS CUTHBERT is an Engineering Manager for Hamilton Health Sciences, and the former manager of Cogeneration and Energy at McMaster University Medical Center in Hamilton, Ontario, Canada. His e-mail address is cuthbchr@hhsc.ca.

TONY CUPITO is a Director of Business Development of IRC Building Sciences Group Inc. His Email address is cutcupido@ircgroup.com.

ELLIOTT JEYASEELAN is a IT \& Embedded Technologies Specialist for the Dept of Facility Services \& Utilities, McMaster University, Hamilton, On, Canada. His email address is eliotj@mcmaster.ca.

ROBERT FOREST is an Engineer at Carmichael Engineering Ltd. His email address is rforest@carmichael-eng.ca.

MICHAEL BOBKER is a Director of Building Performance Lab, CUNY Institute for Urban Systems. His email address is michael.bobker@baruch.cuny.edu.

JANINE BELFAST is principal of Optimal Green Operations and Research Associate at CUNY Building Performance Lab. Her email address is jbelfast@ogreeno.com. 